\title{
The effect of mode of transport on intraindividual variability in glycemic and insulinemic response testing
}

Article

Accepted Version

El-Chab, A. and Clegg, M. E. (2018) The effect of mode of transport on intraindividual variability in glycemic and insulinemic response testing. International Journal of Sport Nutrition and Exercise Metabolism, 28 (3). pp. 253-258. ISSN 1543-2742 doi: https://doi.org/10.1123/ijsnem.2017-0250 Available at https://centaur.reading.ac.uk/80382/

It is advisable to refer to the publisher's version if you intend to cite from the work. See Guidance on citing.

To link to this article DOI: http://dx.doi.org/10.1123/ijsnem.2017-0250

Publisher: Human Kinetics

All outputs in CentAUR are protected by Intellectual Property Rights law, including copyright law. Copyright and IPR is retained by the creators or other copyright holders. Terms and conditions for use of this material are defined in the End User Agreement.

www.reading.ac.uk/centaur 
Central Archive at the University of Reading

Reading's research outputs online 


\section{AbSTRACT}

2 The effect of light to moderate intensity exercise, such as that used as a mode of transport, on glycaemic 3 response (GR) testing is unclear. The aim was to investigate the effect of acute exercise (walking and 4 cycling) simulated to act as a mode of transport, prior to GR testing on the intra-individual variability of 5 blood glucose and insulin. Eleven male participants visited the laboratory four times. Initially they 6 undertook a $\mathrm{VO}_{2} \max$ and two submaximal exercise tests. For the other three visits they either rested (25

$7 \mathrm{~min}$ ), cycled or walked $5 \mathrm{~km}$ followed by a two hour GR test after consuming a glucose drink (50g 8 available carbohydrate). The mean $\mathrm{CV}$ of each transport group was below the International Organisation 9 for Standardisation cut off of $30 \%$. The highest mean coefficient of variation (CV) of glucose area under 10 the curve (GAUC) was between the rest and walking trials (30\%) followed by walking and cycling (26\%). 11 For insulin AUC (IAUC) the highest mean CV was between walking and cycling (28\%) followed by rest 12 and walking (24\%). The lowest GAUC and IAUC were between rest and cycling (25\% and $14 \%$, 13 respectively). The current study also did not find differences $(p>.05)$ between the conditions for GAUC 14 (rest: $134.5 \pm 104.6$; walking: $115.5 \pm 71.7$; cycling: $142.5 \pm 75 \mathrm{mmol} \cdot 120 \mathrm{~min} \cdot \mathrm{L}^{-1}$ ) and IAUC (rest: 19.45 $15 \pm 9.12$; walking: $16.49 \pm 8.42$; cycling: $\left.18.55 \pm 9.23 \mu \mathrm{mol} \cdot 120 \mathrm{~min} \cdot \mathrm{mL}^{-1}\right)$. The results indicate no 16 difference between the tests undertaken however further research should ensure the inclusion of two rest 17 conditions.

19 Keywords: glycaemic index, exercise, standardization 


\section{INTRODUCTION}

21 In 2010, the International Organisation for Standardisation (ISO) published the first edition of guidelines

22 for standardising the determination of glycaemic index (GI) of foods for practice and research purposes

23 (International Standards Office, 2010). According to the report, subjects should avoid vigorous exercise

24 on the morning of the test, as it has been shown to raise whole body glucose uptake and glucose area

25 under the curve (GAUC) (Rose et al., 2001). This will result in an increase in coefficient of variation

26 (CV) between trials and possibly exceed the acceptable level of variability for the reference food of $30 \%$

27 (International Standards Office, 2010). The large within-subject variability for the reference food can

28 decrease the accuracy, precision, and reproducibility of GI (Brouns et al., 2005). People may not exercise

29 in the morning before the test but may walk and cycle in order to commute to these research studies.

30 There has been little agreement on the effect of low to moderate intensity exercise on glycaemic response

31 (GR) testing. Some studies have shown no effect on GR after aerobic exercise (Ben-Ezra et al., 1995;

32 Roberts, Desbrow et al., 2013). Whereas, others have observed a decrease (Bonen et al., 1998) or an

33 increase in GAUC (Knudsen et al., 2014; Rose et al., 2001). Either way, whether it is an increase or a

34 decrease, the CV of the measurement will be affected by this change. Regardless of whether this change

35 leads to a $\mathrm{CV}>30 \%$ or not, researchers should always aim to minimise it in order to improve precision. It

36 should be noted that none of the abovementioned studies reported the CV between trials.

37

38 Understanding the effect of walking and cycling at an average pace of commuting, on blood glucose and

39 insulin levels is particularly important. Subjects may come by bus (rest) to one visit and cycle or walk to 40 another visit. In Oxford Brookes University a significant portion (33\%) of staff and students walk or cycle

41 to the university (Oxford Brookes University, 2016) and any alteration in the type, duration or intensity of

42 this activity may add noise to the results and hence reduce their reproducibility (Brouns et al., 2005).

43 Therefore, the aim of this study was to investigate the effect of acute exercise (walking and cycling) prior

44 to testing on the intra-individual variability of blood glucose and insulin responses. We hypothesised that 
45 performing acute exercise before blood glucose and insulin response testing will increase the intra46 individual variability between trials.

47

48

49

50

51

52

\section{METHODS}

Eleven men (age $26 \pm 4$ years; weight $74.1 \pm 8.1 \mathrm{~kg}$; height $177 \pm 7 \mathrm{~cm} ; \mathrm{BMI} 23.8 \pm 3.1 \mathrm{~kg} \cdot \mathrm{m}^{-2} ; \mathrm{VO}_{2} \max$ $40.6 \pm 6.6 \mathrm{ml} \cdot \mathrm{kg}^{-1} \cdot \mathrm{min}^{-1}$ ) participated in the present study. Eligibility criteria included being male, exercising $\leq 150$ min per week, aged between 18-40 years, and free of metabolic disorders. This study was conducted according to the guidelines laid down in the Declaration of Helsinki and all procedures were approved by the University Research Ethics Committee at Oxford Brookes University.

Participants visited the laboratory four times during the study. They undertook a preliminary test at visit 1, then rest, cycling and walking tests followed by a five minute rest and a two hour GR test for the three subsequent visits given in random order. The GR was measured using the protocol adapted by Brouns and colleagues (2005) and by following the ISO guidelines (International Standards Office, 2010). A summary of the experimental protocol and study design is presented in Figure 1.

For the preliminary test participants arrived at the laboratory after fasting for three hours, avoiding caffeine consumption for 10 hours, having avoided the consumption of alcohol and refrained from any strenuous physical activity for 24 hours. Their height was taken using a stadiometer (Seca, Birmingham, UK) and body composition was measured using Tanita BC-418 (Tanita, Middlesex, UK) body composition analysis.

Then participants completed two submaximal exercise tests followed by a $\mathrm{VO}_{2} \max$ test. The first submaximal test consisted of walking at a steady pace of $5 \mathrm{~km} \cdot \mathrm{h}^{-1}$ and $1 \%$ gradient for 10 min while taking gas measurements to determine the oxygen uptake $\left(\mathrm{VO}_{2}\right)$ using an automated gas analysis system (Metalyzer 3B, Cortex, Germany). This test was used to determine the intensity of walking as a 
71 percentage of $\mathrm{VO}_{2}$ max. Subjects rested for 10 minutes before they completed the second submaximal test

72 which consisted of five stages of cycling exercise. The work load started at 40 Watt (W) and 73 progressively increased by $15 \mathrm{~W}$ every 4 minutes until it reached $100 \mathrm{~W}$ at stage 5 . This was used to 74 determine the work load of the cycling condition. Following the submaximal tests, subjects took a 15 75 minute rest and then performed an incremental ramp exercise test $\left(\mathrm{VO}_{2} \mathrm{max}\right)$ on an electromagnetically 76 braked cycle ergometer (Corival, Lode, The Netherlands). The incrementation rate was 5 W every $15 \mathrm{~s}$ 77 corresponding to ramp slope of $20 \mathrm{~W}$ per minute from a baseline of $20 \mathrm{~W}$. The test was terminated and $78 \mathrm{VO}_{2} \max$ was considered reached when two of the following criteria were met: 1) the participant could no 79 longer sustain a pedalling cadence of at least $60 \mathrm{rpm}, 2)$ a respiratory exchange ratio $\geq 1.1,3$ ) an increase 80 in oxygen uptake $<0.21 \cdot \mathrm{min}^{-1}$ (Howley et al., 1995). For this study, the maximal test was preceded by a 81 submaximal test for practical reasons. It has been shown that maximal oxygen uptake is not affected by 82 varying stages of exhaustion at the beginning of the test (Stamford et al., 1978).

84 During the three experimental visits participants arrived at the laboratory after 10-hours overnight fasting, 85 having avoided the consumption of alcohol and caffeine and refrained from any strenuous physical 86 activity for the last 24 hours as recommended in the ISO guidelines (International Standards Office,

87 2010). They were also instructed to come to the laboratory by bus or driving to avoid exercising prior to 88 testing and standardise physical activity. Participants were asked if they followed the instructions given 89 on their arrival to measure compliance. None of our participants were excluded based on this. Participants 90 were randomised to one of the three following conditions: 1) rest on a chair for 25 min (rest), 2) cycle 5 $91 \mathrm{~km}$ at $50 \% \mathrm{VO}_{2} \max$ (cycling), and 3) walk $5 \mathrm{~km}$ at a speed of $5 \mathrm{~km} \cdot \mathrm{h}^{-1}$ with $1 \%$ inclination equivalent to $9237 \pm 7 \% \mathrm{VO}_{2} \max$ (walking). These conditions were applied to simulate a $5 \mathrm{~km}$ commute to the 93 laboratory. The exercises were not matched for work but instead the distance was fixed to simulate a 94 realistic scenario where participants commute from home which is always at a fixed distance from the 95 laboratory. All conditions were followed by $5 \mathrm{~min}$ rest and by a two hour glucose test. 
97 The chosen distance for walking and cycling was set at $5 \mathrm{~km}$ which was based on two criteria: 1) the average distance travelled to work by trip length and mode in Great Britain (Department for Transport, 2013) and 2) the distance required to apply for a parking permit at Oxford Brookes University (Oxford Brookes University, 2014). According to the national travel survey conducted in 2012, the highest percentage of people (24\%) who used walking, cycling, or taking the bus as mode of transport commuted an average distance of $5.6 \mathrm{~km}$ (Department for Transport, 2013). However, as the distance required to apply for a parking permit at Oxford Brookes University is $>5 \mathrm{~km}$ (Oxford Brookes University, 2014), 5 $\mathrm{km}$ was set as the average distance where most people will most likely use the bus, bicycle, or walking as mode of transport. The speed of $5 \mathrm{~km} \cdot \mathrm{h}^{-1}$ was set based on the preferred walking speed of normal weight adults (Browning et al., 2006).

Capillary blood samples were taken at $-5,0,15,30,45,60,90$, and 120 min following the glucose drink. The glucose drink was ingested at $0 \mathrm{~min}$ and consisted of $250 \mathrm{ml}$ of water mixed with $50 \mathrm{~g}$ of available carbohydrate (Myprotein, Cheshire, UK). Blood glucose was immediately measured using an automatic blood glucose analyser (Glucose 201+, Hemocue, Sweden) who has a CV\% of 1.3\% (APPN, 2015). The accuracy of the analyser was checked daily using a control solution. Following the measurement of blood glucose, $300 \mu \mathrm{l}$ of blood was collected in a microtainer and held on ice until centrifuged at $4000 \mathrm{rpm}$ for 10 min (MicroCentaur, MSE, UK). Blood plasma was pipetted and stored at $-40^{\circ} \mathrm{C}$ where plasma insulin was later analysed using electrochemiluminescence immunoassay using an automated analyzer (Cobas E411, Roche Diagnostics, USA) who has a CV\% of 2\% (Roche Diagnostic USA).

In order to standardise food intake, participants received pre-packaged meals that were consumed on the day before each trial with an unlimited access to water. The diet given was subject-specific, covering their daily energy and nutrient requirements. The pre-packaged meals consisted of cornflakes, whole milk, bread, cheese, butter, tomato, pasta, tomato sauce, apple, and banana. On average the diets provided $50 \pm$ $2 \%$ carbohydrate, $15 \pm 1 \%$ protein, and $35 \pm 1 \%$ fat of the total energy intake. The energy requirement for 
123

124

125

126

127

128

129

130

131

132

133

134

135

136

137

138

139

140

141

142

143

144

145

146 respectively.

\section{RESULTS}

each participant was calculated using a predictive equation (Harris \& Benedict, 1918) and a physical activity questionnaire (IPAQ, 2002). Participants were asked to bring all the leftovers the following day in order to measure their compliance to the diet given before they were cleared to start. Lack of compliance was defined as a \% CV above 3\% for energy, carbohydrate, and protein and above $6 \%$ for fat between trials (El-Chab et al., 2016). None of our participants exceeded these values. The average \%CV for energy, carbohydrate, protein and fat intakes between the three test days were $0.4 \%, 1.1 \%, 1.0 \%$ and $0.7 \%$, respectively.

Statistical analyses were performed using SPSSv.22 (IBM, NY, USA). The GAUC and IAUC were calculated using the trapezoidal model (Food and Agriculture Organization and World Health Organization, 1998). The CV of the AUC values obtained for each condition were calculated $(\mathrm{CV}=100 \mathrm{x}$ mean/SD). Shapiro-Wilk statistic was used to determine the normality of the data. Repeated measure ANOVA with Bonferroni correction was performed to test differences in GAUC and IAUC between the three conditions. Where data were skewed, the Friedman test was used. This study was primarily powered based on the ISO guidelines which recommends the inclusion of a minimum of 10 participants (International Standards Office, 2010). The sample size required to compare the CV was calculated using the equation published by Hopkins (2000) which suggests that 10 participants were needed. Statistical significance was set at $p<.05$. All values are mean \pm standard deviation unless stated otherwise.

All eleven participants completed the trial. Participants exercised at $50 \% \mathrm{VO}_{2}$ max which equates to a workload of $96 \pm 31 \mathrm{~W}$ during the cycling trial. During the walking trial they exercised at $37 \pm 8$ $\% \mathrm{VO}_{2} \mathrm{max}$. Mean energy expenditure during cycling and walking were $30 \pm 8$ and $93 \pm 9 \mathrm{kcal}$, 
The highest mean CV of GAUC was observed between rest and walking (30\%) followed by walking and cycling conditions $(26 \%)$, while the variability between rest and cycling was the lowest $(25 \%)$. On the other hand, the highest mean CV of the plasma IAUC was observed between walking and cycling (28\%) followed by rest and walking (24\%), while the variability between rest and cycling was the lowest (14\%).

There was no difference between blood glucose (rest: $4.4 \pm 0.5$; walking: $4.5 \pm 0.6$; cycling $4.4 \pm 0.3$ mmol $\cdot \mathrm{L}^{-1}$ ) and insulin (rest: $51 \pm 17$; walking: $53 \pm 14$; cycling $57 \pm 21 \mathrm{nmol} \cdot \mathrm{mL}^{-1}$ ) values at baseline $p$ >.05. Temporal blood glucose and insulin response curves following either rest, walking or cycling are presented in Figure 2 and 3, respectively. The GAUC and IAUC at 60 and 120 minutes for all conditions can be found in Table 1. No statistically significant effect was detected between all conditions. Figure 4 presents the paired data between all three conditions.

\section{DISCUSSION}

The present study was designed to determine the effect of acute exercise (walking and cycling) prior to GR testing on within-subject variability of blood glucose and insulin responses and found that the CV of GAUC between rest and cycling was $26 \%$ while the $\mathrm{CV}$ between cycling and walking was $25 \%$. These values are below the $30 \%$ cut-off set by ISO (International Standards Office, 2010) and borderline intraindividual variability of $22-25 \%$ seen in previous studies (Clegg et al., 2011; Williams et al., 2008; Wolever et al., 1985). However, the CV between rest and walking (30\%) matched the acceptable level of variability for reference food as outlined by ISO, however it exceeded the intra-individual variability as seen in previous studies by at least $5 \%$.

However, this data also needs to be considered on an individual basis. In the situation where walking was used as a mode of transport during one test day and rest during another test day the mean CV was $30 \%$. However 5 participants had a CV of greater than 30\%. In this situation, researchers will either 1) need to perform a third test of the reference food in the case where only two were completed, 2) repeat the test 
174

175

176

177

178

179

180

181

182

183

184

185

186

187

188

189

190

191

192

193

194

195

196

197

198

199

that is inconsistent with the other two tests in the case where three were completed, or 3) exclude subjects with large variability (International Standards Office, 2010). So in this case 5 participants would need to repeat the test. What is interesting is that in the rest /cycle comparison where the mean CV was $26 \%$, the number of people with a CV of greater than $30 \%$ was also 5. This implies that different types of exercise have similar effects and implications for GI testing. Furthermore this highlights the major limitation of the current study in not having a second rest trial which can be used as a baseline from which to make comparisons. Without this it is difficult to make any conclusions about whether exercise per se has an effect on GR variability.

In the ISO guidelines, the reference food, usually glucose or white bread, serves as a reference point which other foods (test food) are measured against. Large intra-individual variability for the reference food can decrease the accuracy, precision, and reproducibility of the GI (Brouns et al., 2005). Due to the small numbers of subjects included in GI studies $(n=8-12)$ (Brouns et al., 2005; Foster-Powell et al., 2002; Wolever, Jenkins et al., 1988) poor standardisation can have implications even if the CV is less than $30 \%$. If we were to consider a hypothetical scenario where $180 \mathrm{mmol} \cdot \mathrm{L}^{-1}$ is the GAUC of the reference food in one of the subjects, a $\mathrm{CV}$ of $+25 \%$ (equivalent to $257 \mathrm{mmol} \cdot \mathrm{L}^{-1}$ ) will lead to a GI of 70 whereas a CV of $+30 \%$ (equivalent to $277 \mathrm{mmol} \cdot \mathrm{L}^{-1}$ ) will lead to a GI of 65 (GI = GAUC of reference food divided by GAUC of test food multiplied by 100). In this hypothetical example, walking to the laboratory before the test food and taking the bus before the reference food testing can contribute to an additional 5 point discrepancy in GI. Without the a rest/rest comparison we cannot tell if this discrepancy would be the same following two similar standardisation protocols but it does indicate some limitations in the GI methodology.

Median GAUC and mean IAUC after 120 min were approximately $16 \%$ lower after walking compared to rest, although this difference was not statistically different. These results therefore need to be interpreted with caution given the lack of rest/rest comparison. Bonen and colleagues (1998) showed similar 
200

201

202

203

204

205

206

207

208

209

210

211

212

213

214

215

216

217

218

219

220

221

222

223

224

reduction of $16 \%$ in GAUC but no difference in IAUC after low intensity exercise compared to rest. These findings are supported by previous studies who showed that a single bout of exercise improves insulin sensitivity in muscles (Hayashi et al., 2005; Nazar et al., 1987) leading to a reduced insulin response (Ben-Ezra et al., 1995; Hayashi et al., 2005) and improved glucose tolerance (Bonen et al., 1998; Nazar et al., 1987). However, other studies have also shown contradictory results mainly after high intensity exercise (Braun et al., 1995; King et al., 1995). The differences in GAUC were less pronounced between cycling and rest. A possible explanation for this might be that although cycling had a higher intensity than walking ( $50 \%$ vs. $37 \pm 8 \% \mathrm{VO}_{2} \max$, respectively); it was significantly shorter (14min for cycling and 60min for walking). It could be argued that the total energy expenditure which was higher during walking $(93 \pm 9 \mathrm{kcal})$ compared to cycling $(30 \pm 8 \mathrm{kcal})$ led to the pronounced effect of walking. It has been shown that energy expenditure rather than intensity has more impact on insulin sensitivity (Braun et al., 1995). A $30 \pm 8 \mathrm{kcal}$ of energy expenditure during cycling may not be significant enough to alter glucose response. The large standard deviation might explain the lack of statistically significant difference between walking and the two other conditions.

As outlined above a major limitation of this study is lack of a second rest trial. This would have allowed the calculation of baseline intra-individual variability from which comparisons could have been made within our study group. Another limitation of this study is that we did not measure participants' energy expenditure on the day preceding each visit to make sure it does not vary significantly. However, we did provide instruction to our participants to keep their physical activity level as close as possible the day before each visit and compliance was measured on their arrival to the laboratory. This study did not include female participants; however, we do not consider it as a limitation as there is no difference in GR or impact of exercise on GR between genders (Wolever et al., 2003; Bonen et al., 1998). 
225 The current study did not find any differences in blood glucose following three different modes of 226 transport prior to GR test. We also found that the mean CV of each transport group was below the ISO cut 227 off of 30\%. Differences in CV can have implications for GI values as demonstrated above and future 228 studies should include two rest conditions to allow the calculation of baseline intra-individual variability. 229 This will allow for conclusions to be made as to the possible impact of exercise on GI values. 


\section{ACKNOWLEDGEMENTS}

The authors' contributions are as follows: $\mathrm{AE}$ and $\mathrm{MC}$ contributed to the study design and interpretation of the findings; AE was the principal investigator and contributed to the data collection, data analyses, and writing the manuscript. All authors read and approved the final version of the manuscript. No external financial support was gained for this study.

\section{REFERENCES}

Australian PoCT Practitioner's Network (APPN). (2015, August 15). HemoCue Hb 201+ method and sample collection. Retrieved from http://www.appn.net.au/Data/Sites/1/appn/02implementation/technicalresources/haematology/hemo cuehb201 methodandsamplecollection.pdf

Ben-Ezra, V., Jankowski, C., Kendrick, K., \& Nichols, D. (1995). Effect of intensity and energy expenditure on postexercise insulin responses in women. Journal of Applied Physiology, 79(6), 2029-2034.

Bonen, A., Ball-Burnett, M., \& Russel, C. (1998). Glucose tolerance is improved after low- and highintensity exercise in middle-age men and women. Canadian Journal of Applied Physiology, 23(6), 583-93.

Braun, B., Zimmermann, M. B., \& Kretchmer, N. (1995). Effects of exercise intensity on insulin sensitivity in women with non-insulin-dependent diabetes mellitus. Journal of Applied Physiology, 78(1), 300-306.

Brouns, F., Bjorck, I., Frayn, K. N., Gibbs, L., Lang, V., Slama, G., \& Wolever, T. (2005). Glycaemic index methodology. Nutrition Research Reviews, 18(1), 145-171.

Browning, R. C., Baker, E. A., Herron, J. A., \& Kram, R. (2006). Effects of obesity and sex on the energetic cost and preferred speed of walking. Journal of Applied Physiology, 100(2), 390-8.

Clegg, M. E., Pratt, M., Meade, C. M., \& Henry, C. (2011). The addition of raspberries and blueberries to 
a starch-based food does not alter the glycaemic response. The British journal of nutrition, 106, $335-338$.

El-Chab, A., Simpson, C., \& Lightowler, H. (2016). The reproducibility of a diet using three different dietary standardisation techniques in athletes. European Journal of Clinical Nutrition, 70(8), 954958.

IPAQ. (2002, August). International Physical Activity Questionnaires Ipaq : Short Last 7 Days SelfAdministered Format. Retrieved from https://docs.google.com/viewer?a=v\&pid=sites\&srcid=ZGVmYXVsdGRvbWFpbnx0aGVpcGFxfG d4OjhlMTcxZGJkZmMxYTg1NQ

Department for Transport. (2013, July 30). Department for Transport - How people travel (mode) (NTS03). Retrieved from https://www.gov.uk/government/statistical-data-sets/nts03-modalcomparisons\#table-nts0309

Food and Agriculture Organization and World Health Organization. (1998). Carbohydrates in human nutrition. Report of a joint FAO/WHO expert consultation (Vol. 66). Rome.

Foster-Powell, K., Holt, S. H., \& Brand-Miller, J. C. (2002). International table of glycemic index and glycemic load values: 2002. American Journal of Clinical Nutrition, 76(1), 5-56.

Harris, J. A., \& Benedict, F. G. (1918). A Biometric Study of Human Basal Metabolism. Proceedings of the National Academy of Sciences of the United States of America, 4(12), 370-3.

Hayashi, Y., Nagasaka, S., Takahashi, N., Kusaka, I., Ishibashi, S., Numao, S., ...Tanaka, K. (2005). A single bout of exercise at higher intensity enhances glucose effectiveness in sedentary men. Journal of Clinical Endocrinology and Metabolism, 90(7), 4035-4040.

Hopkins, W. G. (2000). Measures of reliability in sports medicine and science. Sports Medicine, 30(1), 115.

Howley, E. T., Bassett, D. R., \& Welch, H. G. (1995). Criteria for maximal oxygen uptake: review and commentary. Medicine and Science in Sports and Exercise, 27(9), 1292-301.

International Standards Office. (2010). ISO 26642:2010 Food products - Determination of the glycaemic 
index (GI) and recommendation for food classification. Geneva.

King, D. S., Baldus, P. J., Sharp, R. L., Kesl, L. D., Feltmeyer, T. L., \& Riddle, M. S. (1995). Time course for exercise-induced alterations in insulin action and glucose tolerance in middle-aged people. Journal of Applied Physiology, 78(1), 17-22.

Knudsen, S. H., Karstoft, K., Pedersen, B. K., van Hall, G., \& Solomon, T. P. J. (2014). The immediate effects of a single bout of aerobic exercise on oral glucose tolerance across the glucose tolerance continuum. Physiological Reports, 2(8), e12114-e12114.

Nazar, K., Kaciuba-Uściłko, H., Chwalbińska-Moneta, J., Krotkiewski, M., \& Bicz, B. (1987). Plasma insulin and C-peptide responses to oral glucose load after physical exercise in men with normal and impaired glucose tolerance. Acta Physiologica Polonica, 38(6), 458-66.

Oxford Brookes University. (2014). Oxford Brookes University - Parking permit order form. Retrieved from https://www.brookes.ac.uk/about-brookes/sustainability/travel/university-car-parking/parkingpermit-order-form/

Oxford Brookes University. (2016, February). Oxford Brookes University interim travel plan 2016-2018. Retrieved from

https://www.brookes.ac.uk/uploadedFiles/Site_assets/Documents/Travel/Oxford\%20Brookes\%20Interim \%20Trave1\%20Plan\%202016-18.pdf

Roberts, S., Desbrow, B., Grant, G., Shailendra, A.-D., \& Leveritt, M. (2013). Glycemic response to carbohydrate and the effects of exercise and protein. Nutrition, 29(6), 881-885.

Roche Diagnostic USA. (2017, May 04). HemoCue Hb 201+ method and sample collection. Retrieved from https://usdiagnostics.roche.com/en/core_laboratory/instrument/cobas-4000-analyzerseries.html\#menu

Rose, A. J., Howlett, K., King, D. S., \& Hargreaves, M. (2001). Effect of prior exercise on glucose metabolism in trained men. American Journal of Physiology. Endocrinology and Metabolism, 281(4), E766-E771. 
Stamford, B. A., Rowland, R., \& Moffatt, R. J. (1978). Effects of severe prior exercise on assessment of maximal oxygen uptake. Journal of Applied Physiology, 44(4), 559-563.

Williams, S. M., Venn, B. J., Perry, T., Brown, R., Wallace, A., Mann, J. I., \& Green, T. J. (2008). Another approach to estimating the reliability of glycaemic index. The British Journal of Nutrition, 100(2), 364-372.

Wolever, T. M., Jenkins, D. J., Ocana, A. M., Rao, V. A., \& Collier, G. R. (1988). Second-meal effect: low-glycemic-index foods eaten at dinner improve subsequent breakfast glycemic response. American Journal of Clinical Nutrition, 48(4), 1041-1047.

Wolever, T. M., Nuttall, F. Q., Lee, R., Wong, G. S., Josse, R. G., Csima, a., \& Jenkins, D. J. (1985). Prediction of the relative blood glucose response of mixed meals using the white bread glycemic index. Diabetes Care, 8(5), 418-428.

Wolever, T. M., Vorster, H. H., Björck, I., Brand-Miller, J., Brighenti, F., Mann, J. I., ... Xiaomei Wu. (2003). Determination of the glycaemic index of foods: interlaboratory study. European Journal of Clinical Nutrition, 57(3), 475-482. 
321 Table 1. Plasma glucose and insulin areas under the curve during $60 \mathrm{~min}$ and $120 \mathrm{~min}$ of the $2 \mathrm{~h}$ glucose

322 test following either rest, walking or running

\begin{tabular}{|c|c|c|c|c|c|}
\hline & & Rest & Walking & Cycling & $\mathrm{P}$ value \\
\hline \multirow{3}{*}{ GAUC } & $\operatorname{mmol} .60 \mathrm{~min} . \mathrm{L}^{-1}$ & $102.4 \pm 56.5$ & $85.9 \pm 44.8$ & $109.8 \pm 41.8$ & .78 \\
\hline & & & & & \\
\hline & $\operatorname{mmol} .120 \mathrm{~min} . \mathrm{L}^{-1} *$ & $134.5 \pm 104.6$ & $115.5 \pm 71.7$ & $142.5 \pm 75$ & .10 \\
\hline \multirow{3}{*}{ IAUC } & $\mu \mathrm{mol} .60 \mathrm{~min} . \mathrm{mL}^{-1}$ & $13.14 \pm 5.76$ & $10.72 \pm 5.34$ & $12.64 \pm 5.42$ & .23 \\
\hline & & & & & \\
\hline & $\mu \mathrm{mol} .120 \mathrm{~min} . \mathrm{mL}^{-1}$ & $19.45 \pm 9.12$ & $16.49 \pm 8.42$ & $18.55 \pm 9.23$ & .29 \\
\hline
\end{tabular}

323 Values are mean \pm SD.

$324 *$ Values are median \pm SD. 
Visit 1 Participants signed the consent form, height, body composition, $\mathrm{VO}_{2}$ at

329

330

331

332

333

Visit $1 \quad$ submaximal level, and $\mathrm{VO}_{2} \max$ were measured.

334

335

336

337

338

339

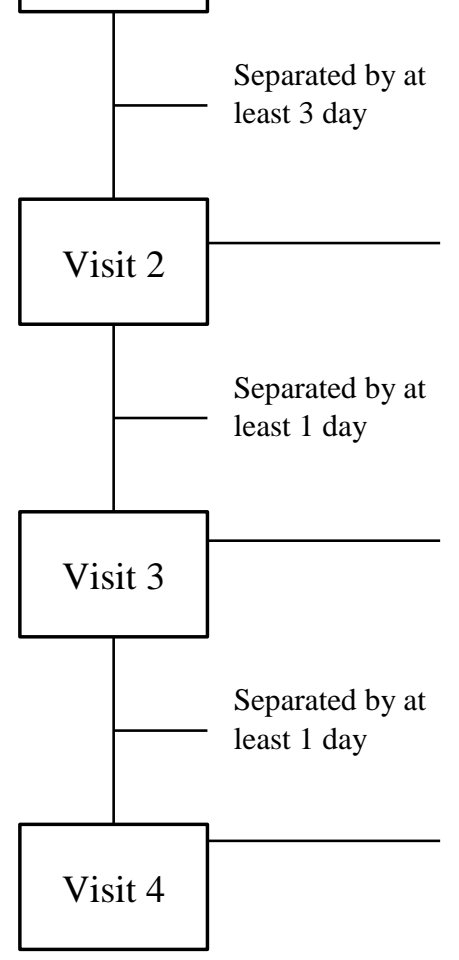

340
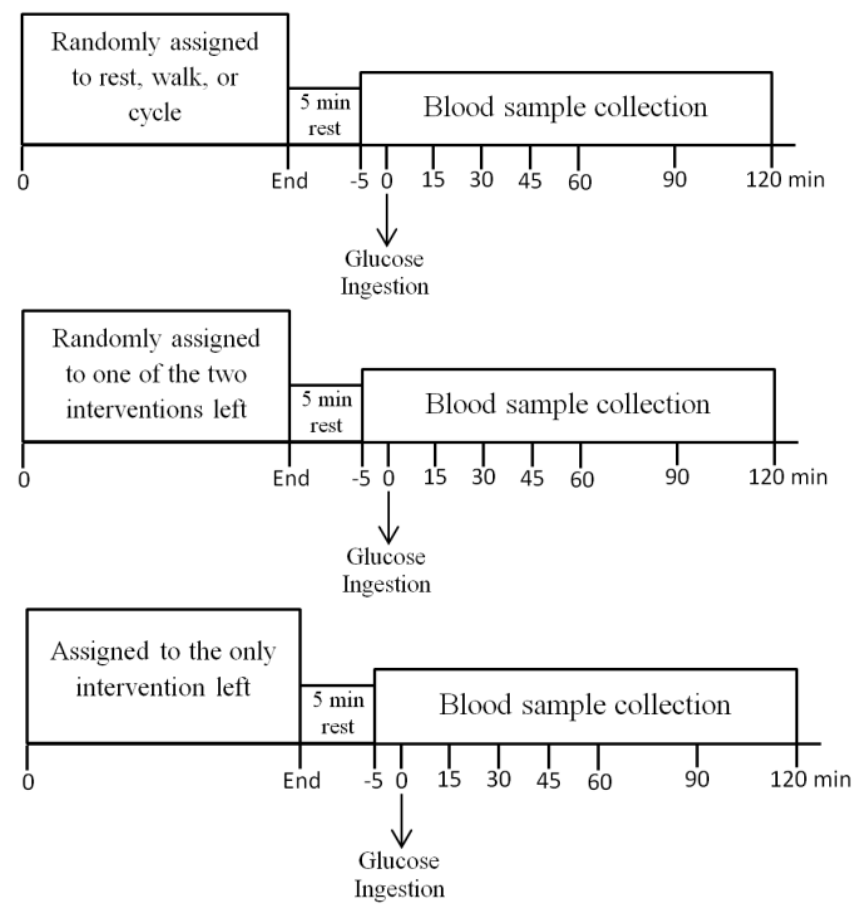

341 Figure 1: Summary of the experimental protocol and study design. 


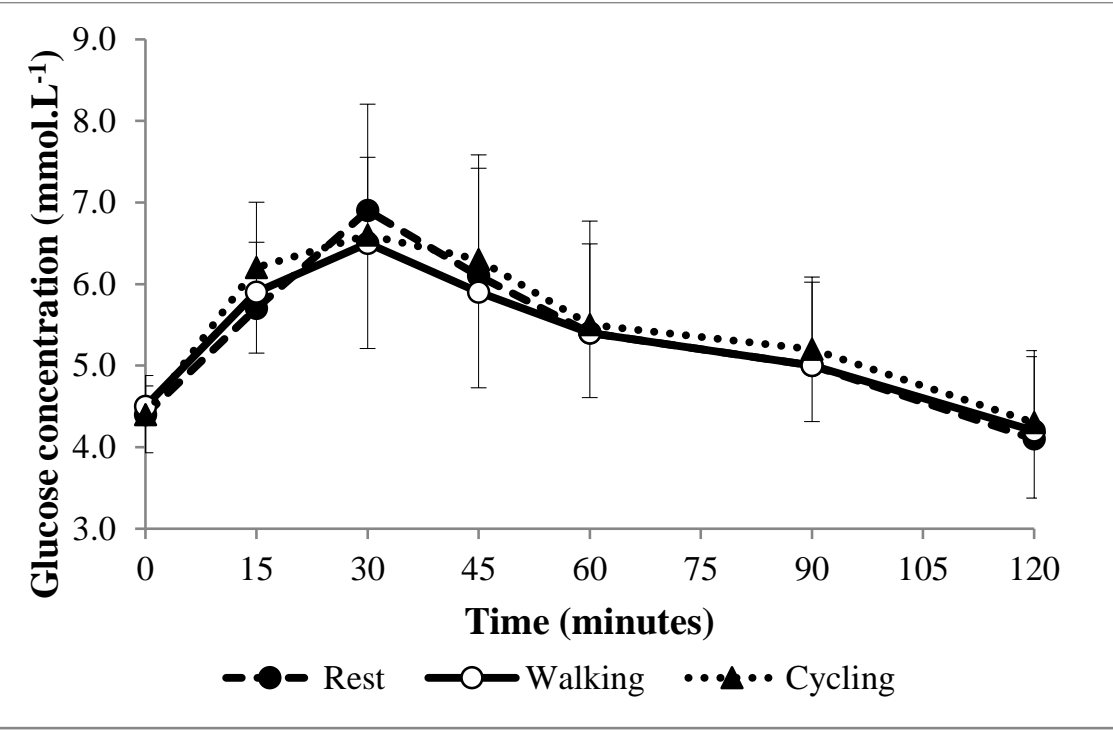

343 Figure 2: Temporal blood glucose response curves following either rest, walking or cycling simulated to 344 act as a mode of transport. Data indicates the median \pm SD. 


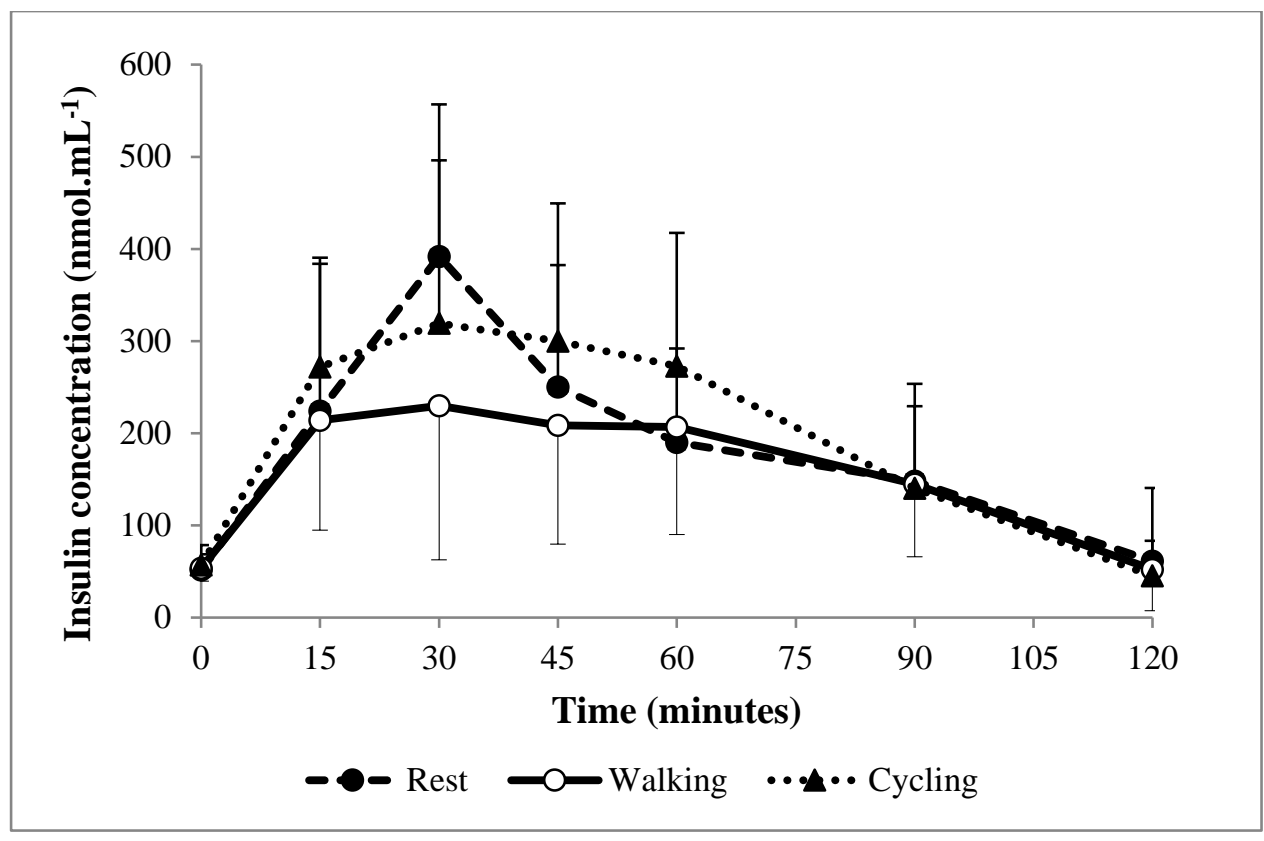

347 Figure 3: Temporal plasma insulin response curves following rest, walking or cycling simulated to act as 348 a mode of transport. Data indicates the median \pm SD. 

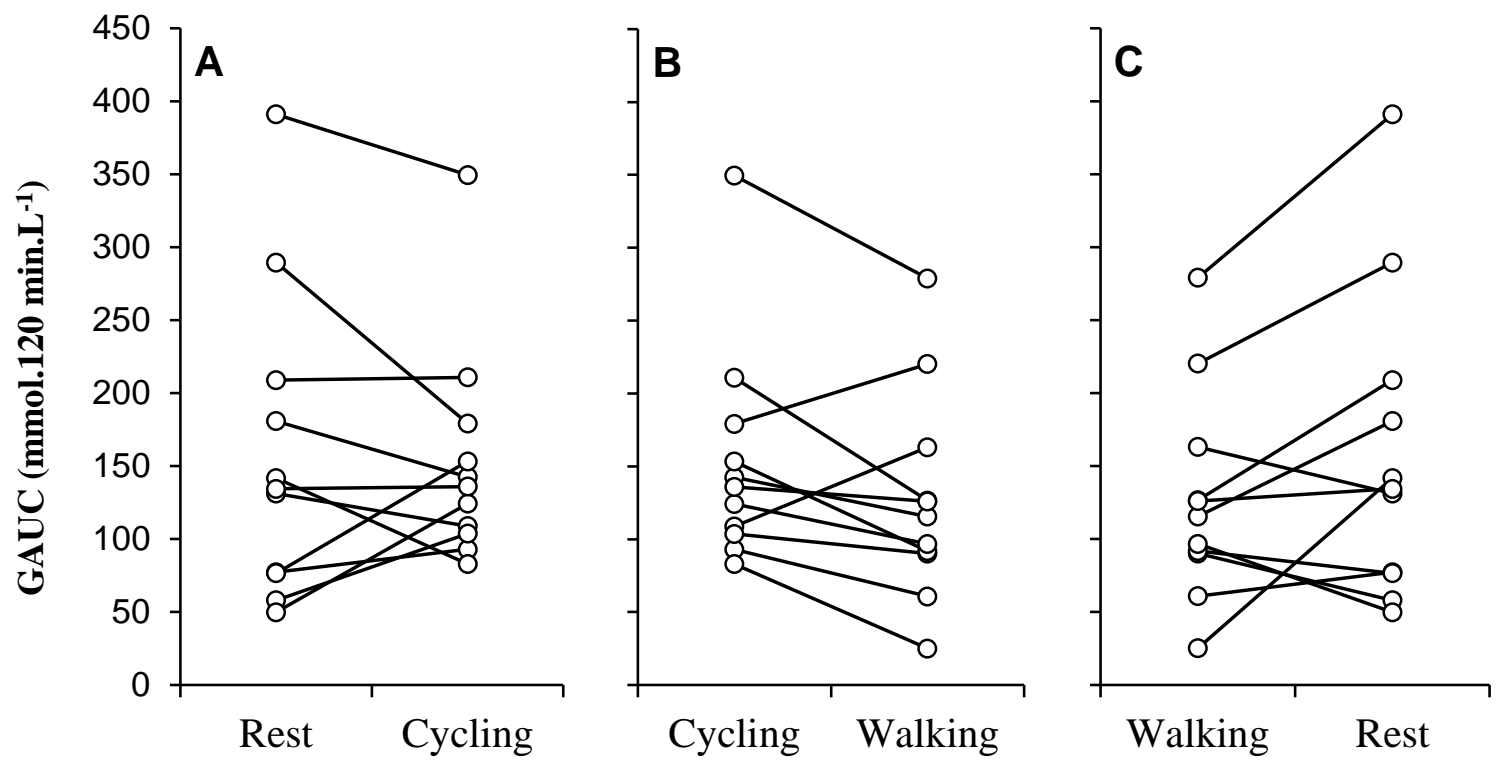

351 Figure 4. Paired data of the incremental blood glucose area under the curve between all conditions. (A)

352 Rest vs. cycling. (B) Cycling vs. walking. (C) Walking vs. rest. 